\title{
Hybrid Diesel-Electric Propulsion Systems
}

\author{
B.K. Chakravarthy \\ CVR College of Engineering, EEE Department, Hyderabad, India \\ Email: bkalyan@gmail.com
}

\begin{abstract}
Recent demands for train traction systems require that they have improved energy efficiency. Issues such as global warming and the depletion of energy resources began to attract attention in society. This system provides regenerative braking which has not been previously possible on conventional diesel-powered trains and enables increased energy savings via regenerated energy. It can be used with urban or sub-urban services with two to three coaches, for shunting purpose or mainline service.
\end{abstract}

Index Terms-Hybrid, Diesel-Electric, VVVF, IGBT Inverter, Battery

\section{INTRODUCTION}

Most systems use a series-hybrid configuration that first converts the engine output into electrical power and uses only motors for propulsion. The AC output generated by the engine-generator set is converted to DC. A Variable Voltage Variable Frequency(VVVF) Inverter drives the Induction motors. Storage batteries are connected to the DC link [1]. The charging and discharging of the storage batteries is controlled using output adjustment of the Converter and Inverter.

\section{Current configurations}

\section{A. Hitachi series hybrid diesel-electric train}
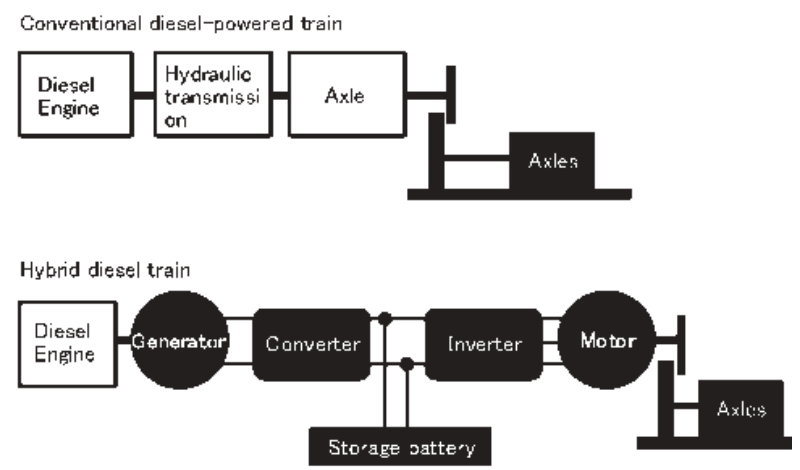

Fig. 1.1: Conventional and Hybrid locomotive configurations.

As shown in Fig 1.1, a conventional diesel powered train, the diesel engine drives axles through a hydraulic transmission. This transmission is sometimes replaced by a generator -motor set, where the motor drives the axles. Control is achieved by placing a suitable power modulator in the electrical connection between the generator and motor.

In a Hybrid diesel train, the diesel engine drives the $\mathrm{AC}$ generator. The output of the AC generator is rectified to produce a DC link. This DC link provides the input to a VVVF inverter, which drives the Induction motors. Storage batteries are connected to the DC link. Charging and discharging of storage batteries are controlled by the output adjustment of converter and inverter. The diesel engine-generator set can run at a fixed speed irrespective of the train speed.

\section{B. System Control}

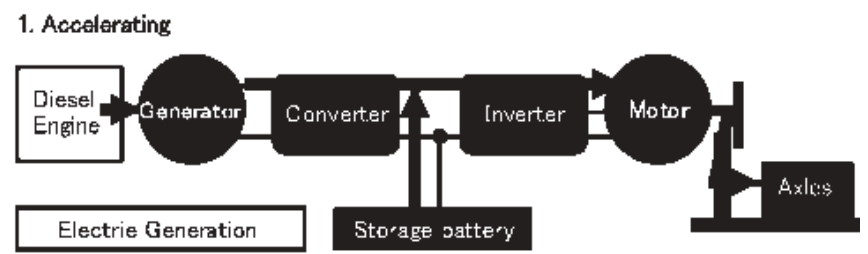

Fig. 1.2: Power flow during acceleration.

As shown in Fig 1.2, the train starts by using the power from the batteries. In the mid-speed range, additional power required is supplied by the enginegenerator set.

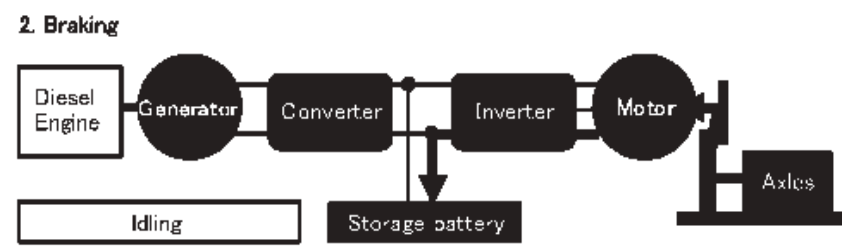

Fig. 1.3: Power flow during braking.

As shown in Fig 1.3, the engine is shut down and the regenerated power from the motor, which is now working as a generator is used to charge the batteries.

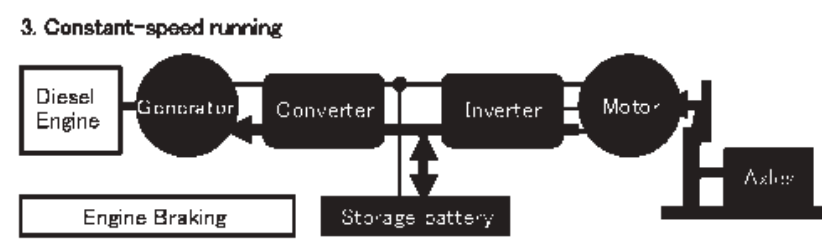

Fig. 1.4: Power flow during constant speed running

Power from both sources is used during constant speed running. To brake at constant speed, engine braking is used. The engine slows down the system and prevents overcharging of the batteries on continuous down-hill gradients. 


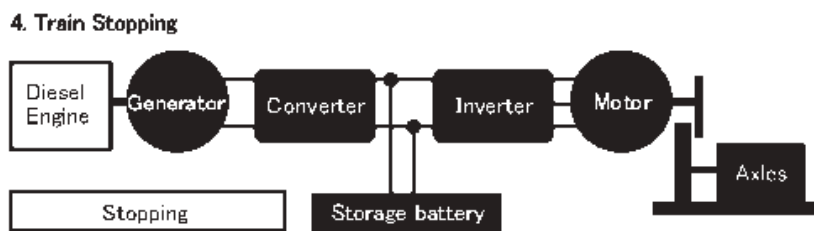

Fig.1.5: Diesel engine is shut down when the locomotive is stationary.

As shown in Fig. 1.5, when the train is stationary, engine is shut-down to prevent noise in stations and it also reduces fuel consumption.

\section{Battery Management}

Stored energy must be maximum in the battery during start-up for achieving high acceleration. Similarly, stored energy should be minimum during start of deceleration for absorbing more regenerated energy. The energy management system ensures that optimum amount of energy is stored in the battery to suit the speed range. The output of the generator is adjusted such that the sum of train kinetic energy and stored energy in the battery is always constant [2].

\section{Converter control at constant power}

To manage the energy balance in the DC link, the converter is controlled at constant power. As the battery is connected in the DC link, converter control at constant voltage is not possible. The DC link voltage varies with the amount of stored energy in the battery. The converter control at constant power allows optimum charge and discharge control of the battery.

\section{Engine Brake Control}

During braking at constant speed, the traction motors generate the braking power. This power flows into the DC link and is distributed between the battery and the converter. The converter is now made to work as an inverter and it drives the alternator as a motor. The engine now acts as a load on the alternator to control the speed. This method provides stable and constant speed under any running conditions.

\section{Toshiba Shunting series hybrid Locomotive}

The shunting hybrid locomotive shown in Figures 1 and 2 uses large capacity high performance batteries. The locomotive can haul a load of 1300 Tons using the power source from the batteries alone. PMSM is used as traction motor. During normal operation, power flows from enginegenerator set and battery to traction motors through the inverter. During braking operation, the regenerated power is used to charge the batteries. The system uses lithium ion batteries. The main battery capacity is high enough to start the locomotive. Modular design has been adopted and each module can be replaced individually. Nitrogen oxides in the emissions were $62 \%$ lower and fuel consumption was $36 \%$ lower when compared to a conventional dieselelectric locomotive. The diesel engine has a power rating of $270 \mathrm{HP}$ while the generator is rated at $173 \mathrm{KVA}$. The maximum power output of the locomotive is $500 \mathrm{KW}$. The locomotive can achieve a top speed of $45 \mathrm{KMPH}$ at full load and a top speed of $110 \mathrm{KMPH}$ at no-load. The system has a modular design. Each module can be replaced with a more recent technology in the future. For example, the diesel engine can be replaced with a fuel-cell and the IGBT based inverter can be replaced with a $\mathrm{SiC}$ hybrid inverter. [8].

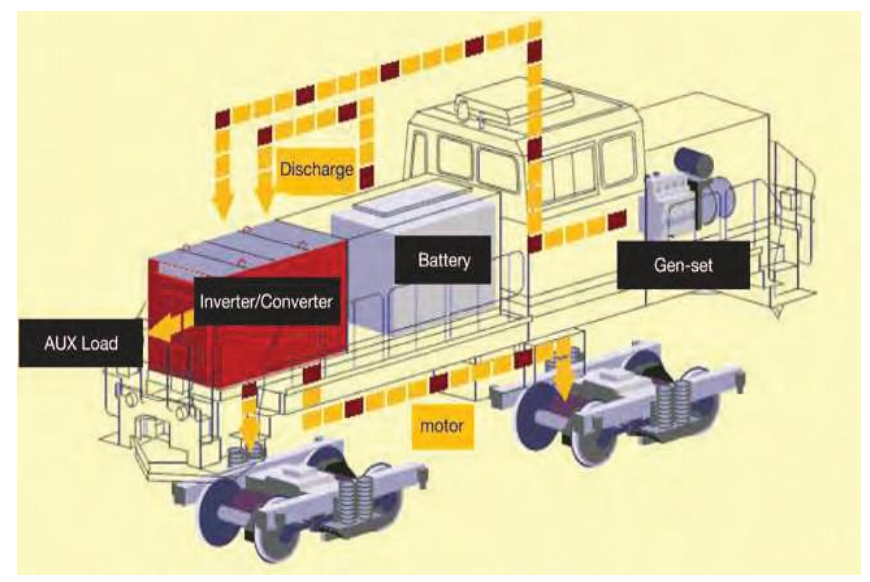

Fig. 2. During acceleration, the control optimizes power flow to the traction motors from both sources or power flows from battery alone.

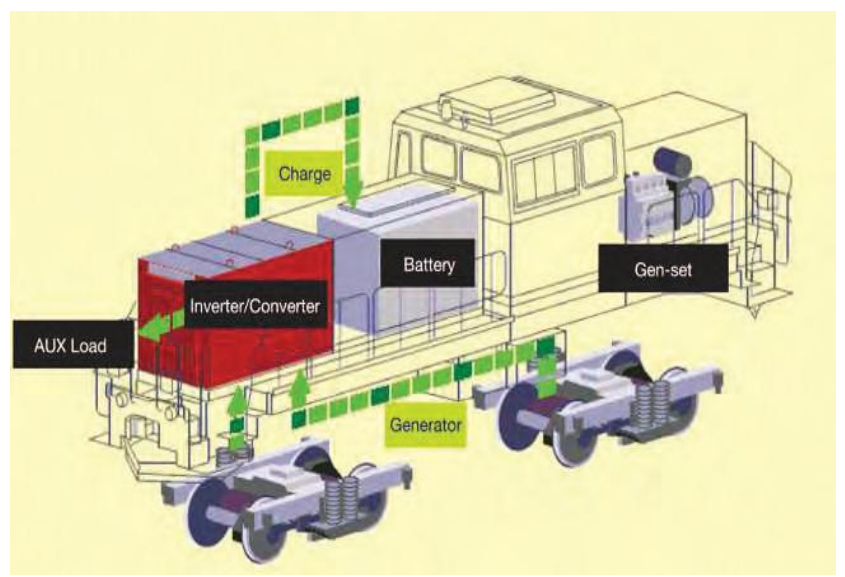

Fig. 3. During deceleration, the power output from the traction motors is used to charge the batteries. The control protects the batteries from over charging or deep discharging.

The locomotive has four inverters connected to four traction motors. Each traction motor is coupled directly to the axle. If a particular inverter or traction motor fails, the locomotive can continue operation with reduced capacity. Redundancy is provided in the battery module. If a battery fails, the locomotive can continue its operation with the defective battery isolated. The converter uses PWM control. The system is controlled by the control unit with a CPU. This control unit controls the converter and inverter for various functions such as acceleration, deceleration and braking. Due to the modular design, maintenance of the locomotive is also simple. If batteries of higher power density are available in the future, they can be used with this locomotive to increase its output power. It also offers the advantages of reduced life-cycle cost and reduced fuel cost. The Permanent Magnet Synchronous Motor (PMSM) used for traction also offers high efficiency [3]. 


\section{Railpower Shunting Hybrid Locomotive}

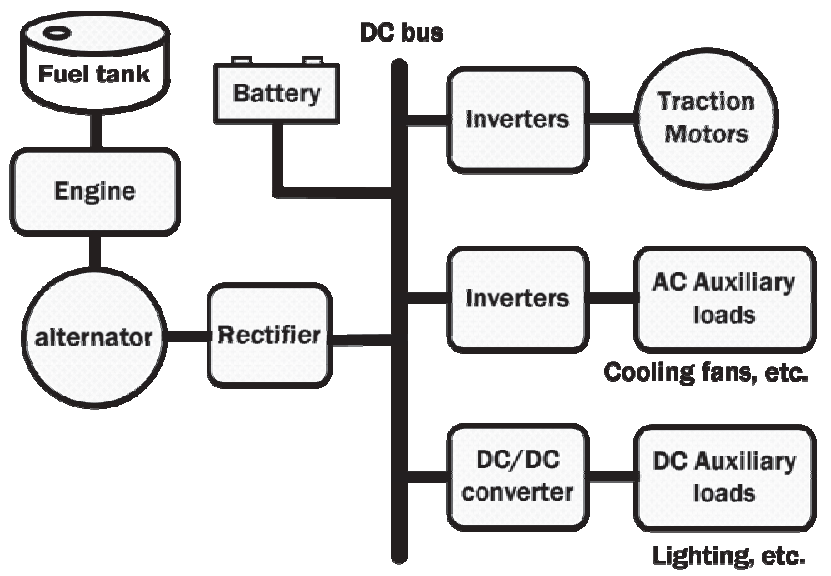

Fig.4 Block diagram of Railpower series hybrid diesel electric locomotive

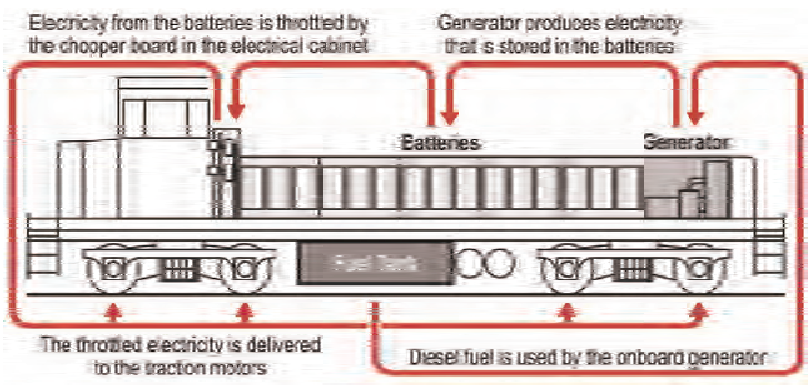

Fig.5 System operation in Railpower hybrid diesel electric locomotive.

As seen in the figure above, the engine -generator set is used only to charge the batteries. The output power from the batteries is supplied to traction motors. This method helps in reducing the idle running time of the diesel engine and contributes to $40-70 \%$ savings in fuel costs and up to $85 \%$ reduction in emissions. The prototype's diesel engine had a power output of $216 \mathrm{KW}$ and a total output of the locomotive was $1490 \mathrm{KW}$.

\section{Application of parallel hybrid technology in main line} diesel-electric locomotives

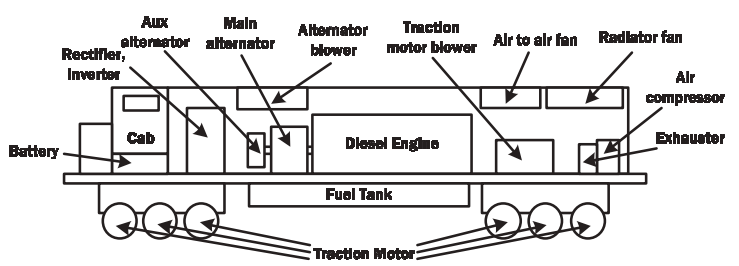

Fig.6 Block diagram of main line diesel-electric locomotive.

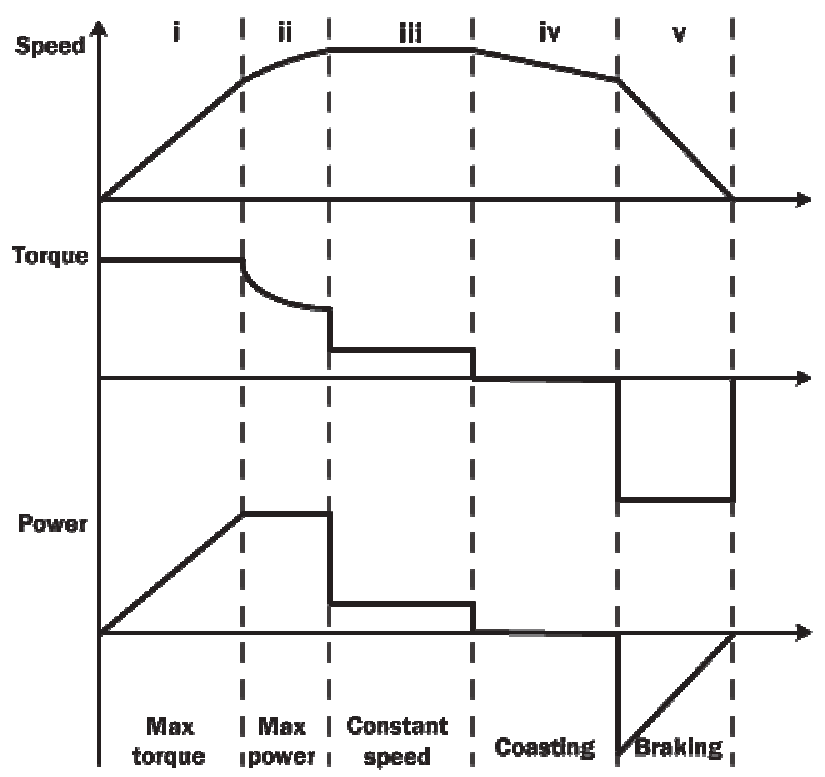

Fig.7 Operating profile of a mainline locomotive.

The basic block diagram and operating profile of a mainline diesel-electric locomotive are shown in figure 5 and figure 6 respectively. Mainline locomotives are used for inter-city service and haul passenger or freight trains. The torque demand is severe during starting and decreases as speed decreases. Torque and power become negative during braking operation. Typical power rating of a mainline diesel-electric locomotive is $4500 \mathrm{HP}$.

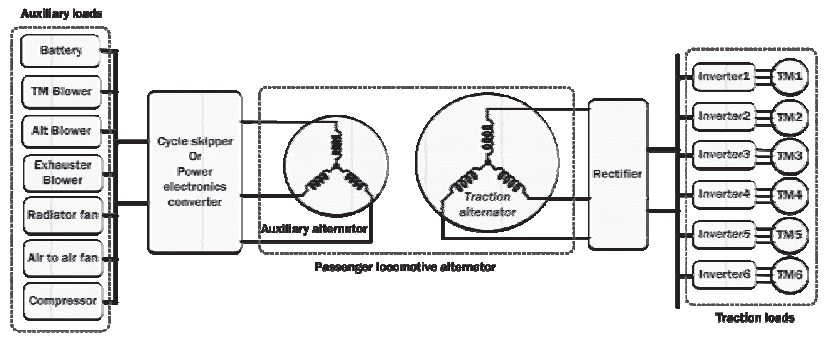

Fig. 8 Electrical connection of alternators in a diesel-electric locomotive with traction motors and auxiliary loads.

The diesel engine drives two alternators connected to the same shaft. The main alternaor supplies power to the six traction motors through the converter-inverter. The second alternator is of lower power rating than the main alternator and supplies auxiliary loads [5]. Each traction motor has a separate inverter. In large locomotives, the power regenerated during braking is stored in batteries. These batteries are Sodium metal Chloride (Lead free) rechargeable batteries. When fully charged, the locomotive can run an additional $2000 \mathrm{KM}$ using the battery power alone. Fuel consumption is reduced by $15 \%$ and emissions are reduced by $50 \%$ compared to a similar diesel-electric locomotive [4].

The locomotive was designed and manufactured by General Electric (GE). It is the only locomotive that meets the most recent emission norms for locomotives in the 
United States. The locomotive has a rated output power of $3280 \mathrm{KW}$ [9].

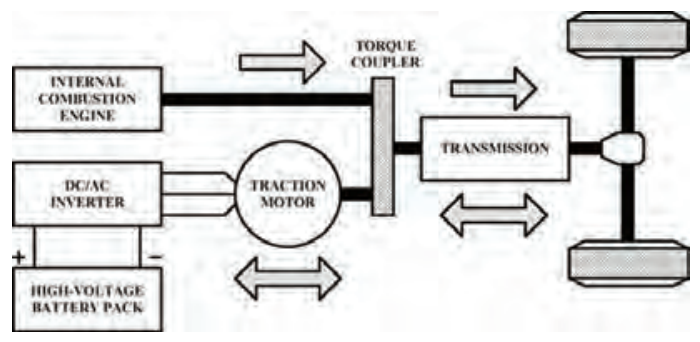

Fig.9 Block diagram of a parallel hybrid system used in mainline dieselelectric hybrid locomotive.

\section{E. Alstom parallel hybrid shunting locomotive}

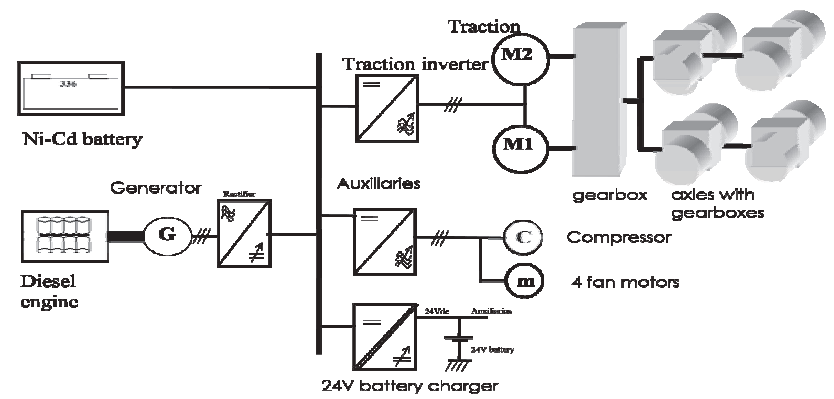

Fig.10 Block diagram of Alstom shunting locomotive using parallel hybrid system.

This locomotive uses Nickel-Cadmium(Ni-Cd) batteries.

The diesel engine-generator set runs at a constant speed irrespective of locomotive speed. The idling time of the engine-generator set is used for charging of the batteries.In normal diesel-electric shunting locomotive, fuel is simply wasted during idling time. Various modes of operation of Alstom locomotive are shown in the figures below [6].

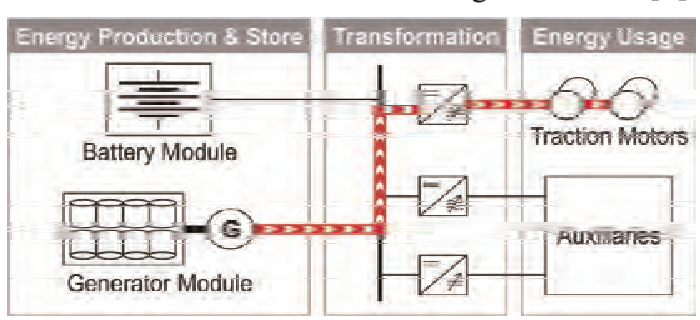

Fig. 10.1 Mode - I: Power flows from diesel engine to traction motors during light load.

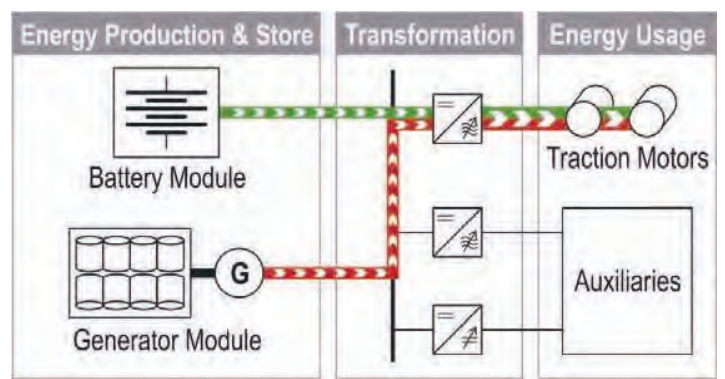

Fig. 10.2 Mode - II: Power flows to traction motors from both sources during heavy load.

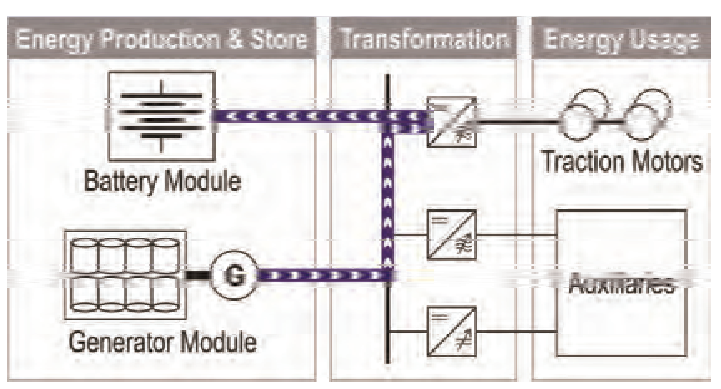

Fig.10.3 Mode - III: Power flows from diesel engine to batteries during idling.

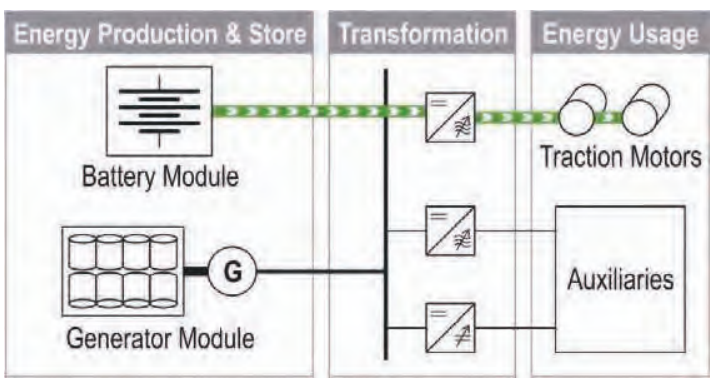

Fig 10.4 Mode - IV: Power flows from traction motors to batteries during braking.

\section{SUMMARY}

\begin{tabular}{|l|l|l|l|l|l|}
\hline \multicolumn{1}{|c|}{ Locomotive } & \multicolumn{1}{|c|}{ Type } & \multicolumn{1}{c|}{ Hybrid system } & \multicolumn{1}{c|}{$\begin{array}{c}\text { Diesel engine } \\
\text { power }\end{array}$} & \multicolumn{1}{c|}{ Total power output } & \multicolumn{1}{c|}{ Battery type } \\
\hline $\begin{array}{l}\text { Hitachi } \\
\text { Ki Ha E200 }\end{array}$ & $\begin{array}{l}\text { Diesel Multiple Unit } \\
\text { (DMU) }\end{array}$ & Series & $330 \mathrm{KW}$ & $430 \mathrm{KW}$ & Li-ion \\
\hline $\begin{array}{l}\text { Toshiba } \\
\text { HD - 300 }\end{array}$ & Shunting & Series & $205 \mathrm{KW}$ & $500 \mathrm{KW}$ & Li-ion \\
\hline Railpower GG-20B & Shunting & Series & $216 \mathrm{KW}$ & $1490 \mathrm{KW}$ & Li-ion \\
\hline GE Evolution Hybrid & Mainline & Parallel & $3280 \mathrm{KW}$ & $550 \mathrm{KW}$ & Sodium metal Chloride \\
\hline Alstom BR-203H & Shunting & Parallel & $200 \mathrm{KW}$ & Ni-Cd \\
\hline
\end{tabular}




\section{CONCLUSIONS}

At present, hybrid technology is best suited for shunting locomotives. A shunting locomotive travels less distance, starts and stops frequently and has a very high idling time when compared to running time. All of these conditions are suitable for effective charging and discharging of batteries in hybrid system. An outstanding advantage of the hybrid system is the possibility of regenerative braking and effective use of regenerated power. With advances in battery technologies, hybrid technology might find wide spread application even in mainline locomotives.

\section{REFERENCES}

[1] Tadashi Soeda, Min Lin, Toshio Hasebe and Akihiko Ujiie, "Electrical Equipments Used in Diesel Hybrid Shunting Locomotive HD300," $9^{\text {th }}$ World Congress on Railway Research, May 22-26,2011.

[2] Dr. Michael Meinert, Siemens AG, "New mobile energy storage system for rolling stock.", 13th European Conference on Power Electronics and Applications, 2009. EPE '09.

[3] Ayman M. EL-Refaie, Electrical Machines Lab, General Electric - Global Research Center, Niskayuna, NY 12309 USA, "Motors/Generators for Traction /Propulsion Applications: A Review "2011 IEEE International Electric Machines \& Drives Conference (IEMDC)

[4] S. Williamson, M. Lukic and A. Emadi "Comprehensive drive train efficiency analysis of hybrid electric and fuel cell vehicles based on motor-controller modeling" IEEE Transactions on Power Electronics Year: 2006, Volume: 21, Issue: 3

[5] J. Baert, S. Jemei, D. Chamagne, D. Hissel, S. Hibon, D. Hegy "Modeling and Energy Management Strategies of a Hybrid Electric Locomotive" 2012 IEEE Vehicle Power and Propulsion Conference.

[6] Ruoyu Hou, Yinye Yang and Ali Emadi "Hybrid electric locomotive powertrains" Transportation Electrification AsiaPacific (ITEC Asia-Pacific), 2014 IEEE Conference and Expo.

[7] www.hitachi-rail.com

[8] www.toshiba.co.jp/sis/railwaysystem/en/products/ locomotive/

[9] www.geglobalresearch.com www.getransportation.com 